\title{
Educação Formal nos Centros Socioeducativos do estado do Ceará
}

\author{
Maria Evylana Alves de Araújo \\ Universidade Estadual do Ceará - UECE \\ Maria Andréa Luz da Silva \\ Universidade Estadual do Ceará - UECE
}

\begin{abstract}
Resumo
0 presente artigo é oriundo da dissertação defendida pela autora para obtenção do título de mestre em Planejamento e Políticas Públicas, cujo tema foi "Educação, Adolescência e Privação de Liberdade: Desafios e possibilidades da Educação Formal nos Centros Socioeducativos do Estado Do Ceará." A pesquisa que deu origem ao presente artigo foi realizada com técnicos da Superintendência do Sistema Estadual de Atendimento Socioeducativo SEAS, Secretária de Educação do Ceará-SEDUC, pedagogos, professores e socioeducandos de centros socioeducativos do Ceará. Onde abordamos questões que nos possibilitasse conhecer como acontece o processo de escolarização dos adolescentes privados de liberdade nos centros socioeducativos, observando o proposto nas políticas de educação voltadas para o ensino regular e sistema socioeducativo sempre fazendo um paralelo com a realidade encontrada.
\end{abstract}

Palavra-chave educação no sistema socioeducativo; socioeducação; adolescente privado de liberdade.

\begin{abstract}
This present article comes from the dissertation defended by the author to obtain the title of Master in Planning and Public Policy, whose the theme was "Education, Adolescence and Deprivation of Freedom: Challenges and possibilities of Formal Education in the Socio-educational Centers of the State of Ceará." The research that originated this article was carried out with technicians from the Socio-educational Assistance System Superintendence of State SEAS, Secretary of Education of Ceará - SEDUC, educators, teachers and Socio-educators of the Socio-educational Centers of Ceará. Where we address the issues that would allow us to know how the schooling process of adolescents deprived of liberty in the socio-educational centers happens, observing the proposed in the education policies aiming the regular education and socio-educational system always making a parallel with the reality found.
\end{abstract}

Key-word education in the socio-educational system; socio-education; adolescent deprived of liberty. 


\section{Introdução}

O termo socioeducação é relativamente novo e ainda pouco explorado pelos estudiosos. No âmbito da sociedade civil, tanto o termo como o próprio sistema são pouco conhecidos, o que leva o grupo para uma certa invisibilidade social. E convém ressaltar que a ignorância sobre o tema é o principal fator a fomentar o preconceito acerca do assunto, daí a importância e a necessidade de ampliarmos os estudos sobre o tema, trazendo para a sociedade que a socioeducação existe, não é uma ilha, e precisa sair da invisibilidade e tomar posse da sua importância no meio social.

É importante frisar que, dentro dos centros socioeducativos de internação, está parte do mesmo grupo etário (adolescentes e jovens) que nossa Carta Magna diz que (junto às crianças) deve ser atendido com absoluta prioridade nas mais diversas áreas, entre elas a educação.

A educação é garantida como direito na Constituição Federal Brasileira de 1988 e no Estatuto da Criança e do Adolescente (1990). Não só no Brasil, "o direito à educação é reconhecido e consagrado na legislação de praticamente todos os países", afirma Gadotti (2005, p.1). Em uma sociedade que reconhece os valores da cultura letrada, "quando falamos de educação já não discutimos se ela é ou não necessária. Parece óbvio, para todos, que ela é necessária para a conquista da liberdade de cada um..." complementa Gadotti (2009, p. 17).

O pedagogo Antônio Carlos Gomes da Costa, um dos principais nomes na luta e elaboração do Estatuto da Criança e do Adolescente (1990), também responsável por cunhar o termo socioeducação, declara que "a natureza essencial da ação socioeducativa é a preparação do jovem para o convívio social” (2006, p. 14). Afirma também que a socioeducação é composta por educação formal, educação profissional, atividades artísticoculturais, abordagem social e psicológica, práticas esportivas e assistência religiosa (COSTA, 2006). Conforme o autor, todas as atividades e ações socioeducativas devem ser trabalhadas com o propósito de desenvolver o potencial do adolescente, tomando-o apto a ser e conviver, isto é, prepará-lo para relacionar-se consigo mesmo e com os outros.

Conforme mencionado, a educação formal está dentro do contexto da socioeducação e possui um papel muito importante no processo de socialização do adolescente. No entanto, ao falar de educação no sistema socioeducativo, é necessário ressaltar de que educação estamos falando, e neste caso a atenção será dirigida à educação formal.

O Sistema de Garantia de Direitos da criança e adolescente se articula para propiciar uma maior fluidez às políticas que defendem, controlam e promovem os direitos das crianças e adolescentes. Ainda assim, diante da importância da educação para a formação integral do ser, da importância dessa garantia de direitos e da existência de um considerável número de adolescentes que se encontram reclusos nos centros socioeducativos, um ponto pede atenção: estaria a Constituição Federal (1988), no seu Art. 205, onde diz que "a educação, direito de todos e dever do Estado e da família" e no Art. 206, inciso I, onde fala que deve haver "igualdade de condições para o acesso e permanência na escola", sendo cumprida? Em outras palavras: estariam os adolescentes privados de liberdade gozando do seu direito à educação? E como está sendo ofertada a educação formal dentro dos centros socioeducativos? Estaria, a educação ofertada, em condições de igualdade com a educação que seria ofertada a esse adolescente caso estivesse gozando de liberdade?

Diante da inquietude causada pelos questionamentos citados, demos início a uma busca na literatura e, posteriormente, no campo de pesquisa, com o intuito de conhecer e 
compreender como vem sendo trabalhada a educação formal com o adolescente em cumprimento de medida socioeducativa em meio fechado no Estado do Ceará, considerando a fala de Freire (1975), quando colocou que a educação não pode ser analisada de forma abstrata e isolada da realidade que a cerca.

\section{O processo de escolarização nos Centros Socioeducativos do estado do Ceará}

Quando falamos em educação formal, é comum nos remetemos à escola, mas não é correto colocá-la apenas como o local onde o ensino acontece. Macedo (2013, p. 719) defende que, para conseguir educar, a escola "precisa colocar o ensino sob suspeita". A autora deixa claro que a ideia não é deixar de ensinar, mas "retirar o ensino do centro nevrálgico da escola" (2013, p. 719). A ideia das colocações acima não é diminuir a importância do ensino, tampouco eleger a educação formal como mais ou menos importante, e sim situá-la dentro do processo, para que a educação formal não seja responsabilizada por algo que não é da sua competência ou tenha seus méritos contestados por desconhecimento sobre seu campo de atuação. Assim, "entendendo a educação como desenvolvimento do próprio espírito e o ensino como teoria em ato" (SAVIANI, 2007, p. 101), podemos dizer que a escola é um espaço de educação e o ensino ocorre dentro do processo educacional.

Gadotti (2005, p. 2) diz que "a educação formal tem objetivos claros e específicos e é representada principalmente pelas escolas e universidades", já a "educação não formal é mais difusa, menos hierárquica e menos burocrática". Coloca ainda que "toda educação é, de certa forma, educação formal, no sentido de ser intencional", embora possa ocorrer em cenários diferentes, e que a "educação não formal é também uma atividade educacional organizada e sistemática". Nesse sentido, o autor segue destacando a importância e a complementariedade de ambas, afirmando que a educação formal pode acontecer fora da escola e a educação não formal pode fazer parte da escola. $\mathrm{O}$ autor destaca também que "Não se trata, portanto, aqui, de opor a educação formal à educação não formal. Trata-se de conhecer melhor suas potencialidades e harmonizá-las em benefício de todos" (2005, p. 3).

Ao afirmar que "a leitura do mundo precede a leitura da palavra", Paulo Freire (1997) elucida que o termo educação vai muito além do espaço escolar, devendo a educação formal considerar todo o aprendizado que o aluno assimilou no decorrer das suas vivências. Gadotti (2005, p. 3) diz que "Hoje as teorias do conhecimento estão centradas na aprendizagem", mas chama atenção para o fato de que "só aprendemos quando nos envolvemos profundamente naquilo que aprendemos, quando o que estamos aprendendo tem sentido para as nossas vidas".

Considerar os conhecimentos prévios e a realidade do aluno nos remete à questão emocional e também à forma como o próprio conhecimento é construído, segundo a teoria de Piaget (2007)1, em que o sujeito só assimila o que tem capacidade de acomodar, então reorganiza suas estruturas, ficando apto a sempre assimilar saberes mais sofisticados2, dentro de um constante processo de equilibração3. Dessa forma, se o interesse é promover

\footnotetext{
1 Epistemologia genética.

2 Independentemente do estágio em que os seres humanos se encontrem, a aquisição de conhecimentos, segundo Piaget, acontece por meio da relação sujeito/objeto. Esta relação é dialética e se dá por processos de assimilação, acomodação e equilibração. 0 dinamismo da equilibração acontece através de sucessivas situações de equilíbrio - desequilíbrio - reequilíbrio que visam, por assim dizer, "dominar" o objeto do conhecimento. (PADUA, 2009, p. 34)

3 Teoria da Equilibração.
} 
o conhecimento, é importante considerar que este não poderá ser meramente transmitido, mas produzido pelo sujeito sempre considerando suas estruturas atuais, também seus interesses e motivações.

De modo geral, "à escola foi delegada a função de formação das novas gerações em termos de acesso à cultura socialmente valorizada, de formação do cidadão e de constituição do sujeito social" (BUENO, 2001, p. 5). E com tantas mudanças, a escola tornou-se um espaço que recebe um público cada dia mais diverso e plural. Conforme Bueno (2001), embora isso já acontecesse no passado, os processos de urbanização parecem ter delegado ainda mais à escola esse papel de formador dos sujeitos, sendo um espaço social privilegiado de convivência e ponto de referência fundamental para a constituição das identidades de seus alunos.

Abramovay (2002, p. 42) chama atenção para o fato de que, nas sociedades modernas, "o estudo é cada vez mais um requisito para o acesso às oportunidades de trabalho e, (...) sem dúvida, é condição essencial à sobrevivência humana.", o que amplia ainda mais a responsabilidade da escola.

Julgamos interessante destacar que essa escola cheia de atribuições à qual estamos nos referindo é a escola pública, que é quem, mesmo diante de tantos desafios e dificuldades, possui a obrigatoriedade de atender gratuitamente toda a nossa sociedade, onde também se incluem os adolescentes e os jovens em cumprimento de medida dentro dos centros socioeducativos.

Ao olhar o socioeducando como portador do direito à escolarização/educação formal (que é realizada pela escola) e aliar isso ao fato de ele estar privado de liberdade, dentro de um centro socioeducativo, sob custódia do estado, compreendemos que para o socioeducando ter seu direito de escolarização garantido, o centro socioeducativo deverá ser ou ter uma escola, ou o socioeducando deverá ser levado até uma unidade que contemple sua necessidade de ensino, conforme prevê o Art. 12 da Resolução no 3/2016 $\mathrm{CNE} / \mathrm{CEB} / \mathrm{MEC} 4$.

Antes da busca pela forma como ocorre o ensino, é importante buscar compreender qual o papel da escola no centro socioeducativo, e encontramos em Oliveira (2014, p. 95) que "no contexto socioeducativo a escola tem como função contribuir para a ressignificação do ato infracional praticado pelo adolescente e também para a modificação de suas trajetórias de desenvolvimento". De acordo com a autora, tal contribuição dar-se-á através das relações interpessoais construídas entre os sujeitos.

A educação, em si, tem um caráter social e, na socioeducação, esse aspecto se apresenta de forma bem acentuada. Costa (2006) afirma que ante à sua complexidade e diversificado conjunto de atores, o conceito de educação encontrado na socioeducação é inteiramente contemplado na ideia conceituada por Darcy Ribeiro na LDB5.

A Lei de Diretrizes e Bases define educação no primeiro artigo como:

\footnotetext{
4 Resolução CNE/CEB no 3/2016 diz: Art. 12 Na impossibilidade de oferta de algum nível, etapa ou modalidade no espaço da unidade de internação, deve ser viabilizado aos adolescentes e jovens o acesso à instituição educacional fora da unidade que contemple sua necessidade de escolarização ou Educação Profissional.

5 Lei de Diretrizes e Bases da Educação Nacional (LBD) (Lei 9.394/96), também conhecida como Lei Darcy Ribeiro.
} 
A educação abrange os processos formativos que se desenvolvem na vida familiar, na convivência humana, no trabalho, nas instituições de ensino e pesquisa, nos movimentos sociais e organizações da sociedade civil e nas manifestações culturais. (Art.1음 da LDB)

Na mesma linha de pensamento, Costa $(2006$, p. 83) propõe "alargar o raio de ação da educação básica". Para ele, a ação significa "tirar os processos educativos não só das quatro paredes da sala de aula, mas também dos muros da escola e da unidade educativa", corroborando com Bueno (2001), quando afirma:

Se a escola, como instituição social, não se limita ao acesso à cultura/conhecimento socialmente valorizado [...] é preciso que, dentro de condições historicamente determinadas, ela procure dar conta tanto do acesso à cultura como de se constituir em espaço de convivência social que favoreça e estimule a formação da cidadania. (BUENO, 2001, p. 6)

Independentemente do espaço em que esteja inserida e do público que venha a atender, a escola é o principal referencial no quesito educação, e esta "é uma prática humana voltada à formação e à constituição do sujeito por meio de processos de internalização de elementos culturais que permeiam a vida em sociedade." (OLIVEIRA, 2014, p. 95).

Em âmbito nacional, o atendimento escolar de adolescentes e jovens em cumprimento de medida socioeducativa é definido pela Resolução CNE/CEB no 3, de 13 de maio de 2016, do MEC. Esta cita entre seus princípios "a escolarização como estratégia de reinserção social plena, articulada à reconstrução de projetos de vida e à garantia de direitos" (Art. 4⿳⺈, Inciso II). Com isso, percebemos um alinhamento entre o proposto para o sistema socioeducativo pela resolução específica e as ideias dos teóricos acima mencionados. Sob essa ótica, analisamos os resultados encontrados na nossa pesquisa sobre o atendimento escolar ofertado nos centros socioeducativos do Ceará.

Ao dirigir o olhar para o processo educativo de uma instituição escolar, faz-se necessário buscar seu documento base, o Projeto Político Pedagógico (PPP). Toda ação educacional possui um propósito, ainda que não esteja explícito, e no caso da res publica esse propósito precisa estar explícito e definido de acordo com as diretrizes que o regem.

Constatamos junto a técnicos da SEAS e equipe pedagógica dos centros que não existe um PPP para cada unidade, e sim uma proposta pedagógica institucional. A Proposta Pedagógica Institucional6 a que se referem trata-se de uma coleção com quatro volumes, datados de 2015, que são: livro 1, Fundamentação Contextualizada; livro 2, Programa de Atendimento Socioeducativo de Internação Provisória; livro 3, Programa de Atendimento Socioeducativo de Internação; e livro 4, Programa de Atendimento Socioeducativo de Semiliberdade. As propostas possuem um alinhamento com as ideias propostas pela SINASE, mas é possível notar uma certa distância do centro socioeducativo. A equipe pedagógica da SEAS afirmou que reconhece a necessidade de projeto político pedagógico para cada unidade e que já estão em processo de formulação.

Quanto à pergunta sobre a existência de PPP à equipe da SEDUC, afirmou-se:

6 Disponível em: https://www.seas.ce.gov.br/proposta-pedagogica/. Acesso em: 12 jul. 2019. 
Bom, eu não posso te responder pelo centro. Mas a escola tem um projeto político pedagógico. Porque é assim: todos os alunos dos centros socioeducativos (de Fortaleza), que estão matriculados, eles estão vinculados a uma escola da nossa rede estadual, e essa escola é o Centro de Educação de Jovens e Adultos. 0 CEJA José Walter. (Entrevistado 1, Grupo Focal SEDUC, grifo nosso)

Na ocasião, podemos afirmar que não existe uma escola exclusiva, da rede estadual ou municipal, dentro de cada centro socioeducativo do Ceará, o que existem são salas de aula que, embora sejam providas e equipadas pelos órgãos responsáveis, ficam a quilômetros da sua sede. Isso é apontado pelos técnicos da SEDUC como um ponto que dificulta o acompanhamento do processo educacional daqueles alunos, gerando um grande desafio para a gestão da unidade escolar7.

Em conformidade com o Termo de Cooperação Técnica no 002/20178, de 17 de fevereiro de 2017 (Processo ${ }^{\circ}$ 17077041-9), celebrado entre SEAS, SEDUC e SME9, o ensino aos alunos/socioeducandos em cumprimento de medidas de internação é ofertado dentro dos centros socioeducativos do Ceará, onde o ensino fundamental II e ensino médio ficam sob responsabilidade do estado e o ensino fundamental I fica a cargo do poder municipal. 0 centro fornece o espaço e as salas são montadas e equipadas pelos órgãos de educação, com mobília, material didático e pedagógico e professores para cada área e modalidade.

Segundo técnico da SEAS todos os socioeducandos que estão nos centros socioeducativos estão estudando e inseridos no censo escolar, na modalidade EJA. Quando indagados sobre como proceder em casos em que o socioeducando estiver abaixo da idade apropriada para frequentar a EJA10, técnicos da SEDUC e da SEAS reconhecem que esse é um desafio a ser superado, mas que ainda não possuem uma solução legal11.

A solução para essa questão também seria parte do cumprimento da meta 7 do Plano Estadual de Educação12, que traz o caso como estratégia, onde versa:

7.43. garantir o acesso à educação regular, com carga horária prevista na LDB, aos adolescentes com menos de 15 (quinze) anos em cumprimento de medida de internação no sistema socioeducativo, assegurando a efetividade das normas da Lei no 8.069/90 e da Lei no 12.594/2012. (CEARÁ, 2016)

\footnotetext{
7 Conforme técnicos da SEDUC, embora o CEJA José Walter acolha todas as matrículas dos socioeducandos da capital, ele não é exclusivo para sistema socioeducativo e recebe matrículas da comunidade em geral (dados coletados no Grupo Focal SEDUC).

8 Termo segue em anexo.

9 Sendo que a SME responde apenas por Fortaleza.

10 De acordo com o Conselho Nacional de Educação, é de 15 anos para o ensino fundamental e de 18 anos para o ensino médio.

11 Ressaltaram ainda que aparecem poucos casos, considerando que a maioria dos socioeducandos já tem 15 anos ou mais e já podem ser atendidos pela EJA ensino fundamental e que, devido à grande distorção idade-série que existe no público atendido pela socioeducação, poucos alunos/socioeducandos do ensino médio são menores de 18 anos.

12 Lei estadual no 16.025 , de 30 de maio de 2016.
} 
Quanto ao cumprimento dos 200 dias letivos, tanto técnicos da SEDUC como da SEAS afirmaram fazer de tudo para que eles pudessem acontecer. Porém, embora forneçam estrutura didática, pedagógica e professores, os órgãos de educação estão sujeitos à rotina do centro socioeducativo onde ele acontece, inclusive na obediência às normas de segurança. Também no contraponto da garantia do tempo pedagógico está o próprio Termo de Cooperação13, nele ficou acordado a oferta de 3 horas de aula diárias, de segunda a sexta, excetuando a quarta-feira, que fica destinada ao planejamento dos professores. 0 ensino na modalidade EJA presencial realmente exige o mínimo de três horas diárias, mas a diminuição semanal de um dia implica na perda de $1 / 5$ do tempo pedagógico, deixando o aluno ainda mais distante do cumprimento da carga-horária estabelecida no sistema regular, que é de 800 horas ao ano. Chamamos atenção para o tempo pedagógico por ele ser um fator fundamental para a qualidade do ensino.

Dentre os equipamentos educacionais de um espaço escolar, a biblioteca está entre os principais, Fragoso (2002) chama nossa atenção para a importância da biblioteca na escola, frisando sua contribuição para a formação do aluno nos aspectos educativos e culturais. A biblioteca é um espaço onde o saber pode ser nutrido cotidianamente, no entanto, até o momento apenas dois dos centros socioeducativos do estado possuem biblioteca, o Centro Socioeducativo Canindezinho e o Centro de Semiliberdade Mártir Francisca. $\mathrm{O}$ alcance aos livros nos centros ainda é muito limitado, os socioeducandos só os acessam no momento da aula, o que foi manifestado com lamento pelos socioeducandos nos grupos focais; eles queriam ter mais contato com os livros e materiais didáticos.

Em conformidade com o artigo 74 do Regimento Interno das Unidades de Medidas Socioeducativas (2013), cada centro socioeducativo possui uma pedagoga, que é a profissional responsável por planejar, coordenar e desenvolver todas as ações pedagógicas dentro do centro, incluindo as atividades escolares e profissionalizantes, oficinas e atividades recreativas, culturais e esportivas, inclusive pelo acompanhamento do trabalho dos professores.

Os professores que atuam nos centros socioeducativos possuem formação específica para atuar em suas respectivas áreas de ensino, com vínculos empregatícios efetivos ou temporários com a rede municipal ou estadual de ensino. Todos gozam do direito ao tempo de planejamento, e nesse tempo recebem formação específica para cada área. Quando questionados sobre os motivos que os fizeram escolher trabalhar nos centros socioeducativos, a resposta mais apresentada pelos professores foi que gostavam do público. Todos os entrevistados já passaram pelo sistema regular de ensino, e quando convidados a comparar o trabalho nos dois ambientes, foi frisado que o centro é desafiador, mas afirmaram que se sentem mais respeitados pelos alunos do centro socioeducativo do que pelos alunos das escolas regulares que passaram.

Eu trabalhei na regular e na regular não é tão diferente assim! Porque os meninos da regular, [...], as mães não vêm na escola, eles dão bastante trabalho, brigam em sala de aula, a gente tem que fazer aquela intervenção o tempo todo, as salas são superlotadas. Aqui, são menos alunos, e eles têm um respeito maior por nós, né. [...] Mas eles vêm pra sala de aula, eles estudam direitinho, aprendem também, prestam atenção. (Professor 1, Grupo focal com professores no CSA)

13 Termo de Cooperação Técnica no 002/2017, de 17 de fevereiro de 2017, celebrado entre SEAS, SEDUC e SME. 
Posso até complementar nessa questão... a gente sempre vê na mídia, né, casos de professores que foram agredidos em sala de aula. Aqui, se já aconteceu, eu até agora ainda não conheço. (Professor 2, Grupo focal com professores no CSA)

Os professores também apontaram como ponto positivo a quantidade de alunos por sala, por ser no máximo dez alunos, disseram que conseguem dar mais atenção. Quanto às condições de trabalho, alguns professores disseram que estava tudo bem; outros usaram o termo "tranquilo"; outros usaram o termo "tranquilo", mas reclamaram dos poucos recursos materiais: "O material que adentra o ambiente escolar é só aquele... o básico do básico" (Professor 2, Grupo Focal no Centro CSC).

No mesmo Grupo Focal, o Professor 1 acrescenta que, seguindo normas de segurança, muitos objetos não podem ser levados para a sala, impedindo de incrementos simples a uma possível feira de ciências.

Entendemos que a manifestação dessa "tranquilidade" ante à impossibilidade de realizar uma aula mais atrativa e equipada pode ser interpretada como pouca expectativa dos professores sobre o aluno ou como pouco crédito no ensino ofertado no centro socioeducativo em que atuam, e em ambos os casos a situação é preocupante. Sem perspectivas sobre o aluno e/ou sobre o sistema, dificilmente o professor estará motivado e tampouco motivará o aluno a superar os muitos desafios que já enfrenta.

A relação professor-aluno foi um fator muito positivo, além da fala dos professores que disseram gostar do ambiente e dos alunos, os alunos demonstraram que se sentem muito acolhidos pelos professores. A professora do CSA disse que recebe os alunos com um abraço e todos os professores falaram da importância de incentivá-los e tratá-los bem. Sobre a relação com os professores, os alunos dizem:

Aqui você sai da sala de aula querendo mais ainda. Os professores tratam você como se fosse um filho. Você se empolga mais ainda pra ir pra sala de aula. Recebe aquele carinho, aquela atenção, aquela explicação. E lá não (na escola da comunidade), lá é muita gente, né. Os professor só passa no quadro e pronto. (Socioeducando 2, Grupo Focal com socioeducando no CSA, grifo nosso)

Não explica tão bem, né? Como ela explica aqui, nós já entende. (Socioeducando 1, Grupo Focal com socioeducando no CSA).

E fora que essa daqui, ela tem paciência com nós. (Socioeducando 3, Grupo Focal com socioeducando no CSA)

É! Acima de tudo a paciência, né? Pra ensinar. (Socioeducando 1, Grupo Focal com socioeducando no CSA)

Rapaz, é supertranquilo! Todos eles são legal, né. Muit o atencioso, dá muita atenção a nós. (Socioeducando 2, Grupo Focal com socioeducando no CSB)

Boa. Eu gosto! (Risos). (Socioeducando 2, Grupo Focal com socioeducando no CSC)

Na pedagogia da autonomia, Freire (1997) diz que, para ensinar, o educador precisa querer bem aos educandos, fala da necessidade de uma relação afetuosa entre ambos e que não consegue entender a educação como experiência fria, sem alma, sem envolvimento das emoções. Nessa relação, Costa (2006, p. 44) destaca a pedagogia da presença: 
Sem a presença educativa, isto é, sem o estabelecimento de vínculos humanos de consideração e afeto com pessoas do mundo adulto que atuam na unidade ou serviço, a docência e as práticas e vivências resultam pouco produtivas no trabalho desenvolvido com o educando.

É notória a relação de cuidado dos professores para com os alunos dos centros, eles demostraram afeto e muito comprometimento em incentivar os alunos a estudar e buscar um caminho fora da ilicitude.

"Além de ser professor a gente dialoga muito, [...] aí é ... a gente acaba que usando dessa afetividade e fazendo com que elas se interessem mais". (Professor 2, Grupo Focal no Centro CSC)

Mas ante às condições em que vive a maioria dos socioeducandos, os professores apontam que acham difícil que alguns deles sigam estudando se não forem amparados por uma boa política de incentivo ao saírem do centro. Nessa linha, uma das pedagogas dos centros afirmou que às vezes a própria escola ou sistema regular de ensino dificulta o retorno do adolescente aos estudos.

Essa preocupação também é apresentada pela socioeducanda quando é indagada sobre se seguirá estudando quando sair do Centro: "Estudar todo mundo quer... Só não sabe se vai..." (Socioeducando 2, Grupo focal com socioeducando no CSC).

A pesquisadora perguntou o porquê e a socioeducanda respondeu: "Depende né? Lá perto da minha casa não tem vaga." (Socioeducando 2, Grupo focal com socioeducando no CSC, grifo nosso).

Isso abre espaço para uma discussão ainda mais ampla, que iremos apontar mesmo não sendo o foco do que estamos trabalhando nesta pesquisa. Quais são as políticas que esperam esses jovens fora do centro? Será que a socioeducação vai se fazer de verdade se parar de atender esse jovem ao final do cumprimento da sua medida?

Na busca inicial sobre como estava acontecendo a escolarização dentro dos centros socioeducativos, encontramos uma matéria no site da SEAS que nos chamou atenção: "Seas realiza palestra para apresentar modelo de tempo integral"14. Tratava-se de uma palestra sobre um modelo de atividades de uma escola em tempo integral, que aconteceu em 08 de fevereiro de 2019, e a matéria informava que o evento fazia parte das discussões do projeto de criação de um novo modelo de ensino para os centros socioeducativos do Ceará. Considerando que o socioeducando já está em tempo integral dentro do centro, onde por lei deve ter sua escolarização garantida, achamos a ideia bastante pertinente e buscamos ver junto à SEDUC e SEAS se a ideia havia avançado. Ambos afirmaram que sim, no Centro Socioeducativo Dom Bosco, mas ainda está funcionando em caráter experimental.

14 Disponível em: https://www.seas.ce.gov.br/2019/02/08/seas-realiza-palestra-para-apresentar-modelode-tempo-integral/. Acesso em: Acesso em: 21 mar. 2019. 
A equipe da SEDUC demostrou olhar a ideia com entusiasmo e afirmou que hoje no Centro Socioeducativo Dom Bosco já existe aulas manhã e tarde,

\begin{abstract}
“[...] mas a ideia é ela (a escola) ser integrada com as ações complementares que o centro pode desenvolver na linha da arte, cultura, lazer integrando isso no processo curricular para esse adolescente. Então, estamos iniciando um processo lá no Dom Bosco de juntar no nível do planejamento essas ações que eram isoladas, separadas." (Entrevistado 1, Grupo Focal SEDUC)
\end{abstract}

Os técnicos reconhecem que ainda falta muito até chegar no que eles consideram ser o ideal para uma escola em tempo integral, ou escola com atividades integralizadas como eles preferiram colocar. Eles entendem que não basta utilizar o modelo de escola em tempo integral que a SEDUC já possui e colocar para funcionar dentro de um Centro Socioeducativo. Concordamos totalmente com essa colocação, considerando que o centro socioeducativo possui uma série de peculiaridades que uma escola que foi pensada para funcionar fora do sistema da socioeducação não abarcaria; a começar pelas normas de segurança e não deixando de considerar a forma como aquele aluno/socioeducando chegou até aquela escola/centro socioeducativo. Tudo isso precisa ser considerado no projeto político pedagógico da instituição escolar.

Percebemos que, como foi colocado, o projeto de escola em tempo integral nos centros socioeducativos do Ceará ainda está sendo gestado. Mas se ele realmente progredir, pode vir a ser uma ótima alternativa, inclusive na visão de alguns socioeducandos que manifestaram o desejo por ampliação no tempo de aula.

Quando questionados sobre o que poderia melhorar as aulas, recebemos respostas como:

"Eu preferia mais tempo de aula..., nós aprenderia mais ainda." (Socioeducando 2,
Grupo Focal do Centro CSA)

"E além disso tem outra coisa aqui, é que nós (indo para a sala de aula) ainda sai do dormitório. Já vou empolgado, acordo (perguntando), "ei, que horas são aí?" (Socioeducando 2, Grupo Focal do Centro CSA, grifo nosso)

"Ocupar assim a mente, né?" (Socioeducando 1, Grupo Focal do Centro CSA)

Óbvio que não entendemos as falas dos socioeducandos como uma compreensão da importância do tempo pedagógico para sua formação escolar. Mas essas falas mostraram de forma nítida o quanto eles anseiam por atividades que os tirem da inércia de um dormitório e os coloque em contato com atividades onde eles consigam perceber que a vida também pode acontecer dentro de um centro socioeducativo.

Outro projeto que achamos interessante nos centros socioeducativos foi o "Recomece... Desenhando o Futuro", uma proposta trabalhada nos centros de internação provisória. Buscamos sobre o "Recomece" junto aos técnicos de educação da SEAS, da SEDUC, dos Centros Socioeducativos e todos falaram sobre a proposta com grande entusiasmo. Disse a técnica da SEAS: "Esse é o grande lance da secretaria, sabe! [...] o Recomece é um acolhimento da história de vida dele." (Entrevistada 1, SEAS). 
Trata-se de uma proposta pensada para os socioeducandos que estão em internação provisória e passam até 45 dias no centro. Sobre o "Recomece... Desenhando o Futuro", os técnicos responsáveis da SEDUC dizem:

A ideia é acolher esses adolescentes, quando eles chegam, eles vêm com os vínculos afetivos rompidos com a comunidade, com a família, com os amigos. Eles quebraram seus vínculos, foram retirados do seu ambiente e estão obrigados a ficar ali naquele ambiente, público, estatal, a seguir e a obedecer a pessoas que eles não têm nenhum vínculo afetivo. Então, o quê que a gente quer... acolher. É uma proposta de acolhimento em que ele vai ter um mergulho na identidade ou nas identidades que ele assumiu, fazer uma revisão sobre projeto de vida, da sua projeção de vida. (Entrevistado 1, Grupo Focal SEDUC, grifo nosso)

A proposta Recomece é uma série de 22 aulas15, com duração de uma hora e meia cada, que possuem começo, meio e fim. 0 que faz com que uma aula não seja pré-requisito para a outra, permitindo que o aluno acompanhe a aula do dia sem dificuldade, independente da ordem dela no programa.

"As vinte e duas aulas são estruturadas em eixos temáticos, que são identidade, mercado de trabalho, fortalecimento do sujeito, comunicação. " (Entrevistado 2, Grupo Focal da SEDUC)

Os técnicos da SEDUC esclarecem: "A gente não pode nem dizer que (sozinha, a proposta) é um processo de escolarização." (Entrevistado 1, Grupo Focal SEDUC, grifo nosso). Isso não tira o mérito da proposta, mas é um fator extremamente relevante para que possamos compreender sua natureza.

Bem avaliada pelos técnicos, pedagogos e professores, chega a hora de ouvir os socioeducandos. Sobre a proposta "Recomece" os alunos do CSA dizem:

"Esse projeto aí faz refletir bem muito [...] "As atividade faz a gente refletir o que nós quer mesmo da nossa vida" (Socioeducando 2, Grupo Focal CSA)

“Fala sobre o que nós passa lá fora também"; "Nosso objetivo, né... Nós começar de novo". (Socioeducando 1, Grupo Focal CSA, grifo nosso)

"E (propõe) a mudança, né? Se a pessoa quiser de verdade... O futuro é estudar, trabalhar, cuidar da família." (Socioeducando 3, Grupo Focal CSA)

No grupo focal com os socioeducandos do Centro CSB, um socioeducando fez uma fala e os demais sentiram-se contemplados, afirmando:

15 No início eram 45 aulas, mas ouvindo a sugestão dos professores foram aprimorando e ficaram em 22 aulas, afirmaram os técnicos da SEDUC. 
Rapaz, da minha parte, eu acho bastante interessante. Por quê? Porque é uma ajuda que dá pra nós aqui dentro, né, de nós poder ter um esforço nos estudo. Como? Bota pra nós abrir a nossa visão de que realmente os estudo vale a pena. [...] Então o que acho, que o projeto Recomeçar é uma grande influência pra aqueles que realmente querem, que acha que realmente o crime não dá nada. (Socioeducando 2, CSB) 16

No grupo focal com os socioeducandos do CSC, acharam a proposta boa, mas não demonstraram o mesmo nível de entusiasmo. A socioeducanda 2 disse: "Ele (o professor) disse que era mais para o conhecimento de autoestima, cidadania, essas coisas aí..." (Socioeducanda 2, Grupo Focal CSC, grifo nosso).

A outra adolescente complementa:

Eu acho, sei lá... normal... o professor é um bom professor, não sei explicar (risos). [...] Eu participei duas semana dessa aula. Eu fiquei pouco tempo participando dessa aula porque eu fui sentenciada... Essa semana mesmo eu já não participei. (Socioeducanda 4, Grupo Focal CSC)

Os socioeducandos demonstraram interesse pela proposta, apesar da aparente apatia das meninas. E vale salientar que esse descontentamento delas não era apenas em relação ao programa Recomece. O professor disse que era comum elas ficarem desmotivadas nos estudos após receberem a sentença, e citou: "Chegou uma menina novata, era um espetáculo, participava! Quando foi sentenciada ficou, tipo assim, uma menina desinteressada." (Professor 2, Grupo Focal do Centro CSC).

Não existe nada de novo em dizer que, em uma aula, alguém se interessou por uma proposta que o tenha colocado em contato com sua própria realidade. Isso apenas reafirma o que Freire (1977) já dizia, quando propunha que o aluno devia sempre ter sua realidade considerada, até porque ninguém seria capaz de transformar a própria realidade sem que a conhecesse.

A proposta Recomece, apesar de abordar temas muito relevantes e ter essa necessária característica acolhedora e pautada nos 04 pilares da educação (aprender a conhecer, aprender a fazer, aprender a viver junto e aprender a ser), não pode sozinha ser assumida como um processo de escolarização. Ela não apresenta divisão por série ou por disciplina, assim está mais voltada para um projeto complementar que pode tranquilamente atuar junto ao sistema de ensino regular e não substituindo-o.

Na busca pelo histórico das políticas de educação formal ofertadas nos centros socioeducativos, encontramos vários avanços. Destacamos o Termo de Cooperação Técnica entre SEAS, SEDUC e SME; o reconhecimento da necessidade de melhorar o ensino nos centros presente no Plano Estadual de Educação (2016/2024); o projeto Recomece... Desenhando o Futuro; a possibilidade de implantar escolas de tempo integral nos centros; e também um discurso bem alinhado (dos profissionais envolvidos) apontando para o aprimoramento da oferta de ensino.

No entanto, apesar dos avanços citados, a fala de Fialho (2012, p. 158), quando disse que "não importa se o aluno está fora de faixa ou não, o EJA é a única modalidade de ensino

16 Os demais socioeducandos dizem que se sentem satisfeitos com a fala do colega. 
ofertada17" continua sendo atual nos centros socioeducativos do Ceará18, inclusive é a única prevista no termo de parceria firmado pela SEAS, SME e SEDUC. O que acende um alerta, haja vista que além de todas a problemática que a modalidade apresenta, ela ainda é considerada pelo Conselho Nacional de Educação como inadequada para o aluno com menos de quinze anos no ensino fundamental e menos de dezoito no ensino médio.

\section{Considerações Finais}

A educação é crucial para a evolução integral de qualquer pessoa. Conforme Saviani (2011), "a educação é inerente ao processo de desenvolvimento humano". Assim, direcionar atenção para o ensino que é trabalhado dentro dos centros socioeducativos é também uma forma de dizer que o período de reclusão do adolescente em um centro socioeducativo não pode lhe trazer como prejuízo, além de tudo, uma "quebra" no trajeto escolar, que já é tão cheio de percalços entre os que mais ingressam no sistema.

É interessante lembrar que o que hoje chamamos de centro socioeducativo, espaço onde se deve oferecer um tratamento pautado na proteção integral, até pouco tempo era um espaço que operava com a doutrina da situação irregular sob égide do Código de Menores. Não podemos ser ingênuos de imaginar que a promulgação do Estatuto da Criança e do Adolescente por si só seria suficiente para converter toda a cultura segregadora que existia em torno do código que vigorava.

Parte dos adolescentes que fazem os números da evasão das escolas públicas de Fortaleza, por exemplo, são encontrados nos relatórios do CCPHA, que disse que 73\% dos adolescentes assassinados na capital estavam fora da escola há pelo menos seis meses. Também ouvimos dos técnicos da SEDUC e da SEAS, dos pedagogos, dos professores e dos próprios socioeducandos entrevistados que muitos deles, ao chegar nos centros, já não frequentavam mais a escola regular19, ficando a cargo do centro socioeducativo promover seu reencontro com a escolarização. Nessa lógica, assistimos a escola pública, que por motivos diversos não conseguiu manter a frequência do seu aluno na escola regular, reencontrando-o na condição de socioeducando privado de liberdade em um centro socioeducativo.

Não seria sensato romantizar o discurso e jogar a responsabilidade desse processo na conta da educação ou da tomada de consciência de um grupo de profissionais. As limitações são reais e precisam ser enfrentadas como tal. Apesar dos termos com cunho social e educativo, o centro socioeducativo continua sendo o local que pune o adolescente que cometeu um ato infracional. Usar o termo "dormitório" não faz com que o adolescente não se sinta em uma "cela". Quando diz que gosta de assistir aulas porque sai do dormitório, o adolescente deixa claro que não é a aula que o atrai e sim a sensação de liberdade que a sala representa naquele momento.

Quando analisamos o ensino que acontece nos centros socioeducativos do Ceará, constatamos o quanto o processo se mostra distante da estrutura básica de uma escola regular. No entanto, corroboramos com Julião (2016) quando ao trazer a discussão sobre

17 Na ocasião, Fialho se referia ao CEPA.

18 Excetuando o Centro Socioeducativo Dom Bosco que, conforme mencionado anteriormente, está em implantação de um modelo de escola em tempo integral.

19 Não tivemos acesso a dados exatos sobre o número de adolescentes que ao chegar nos centros socioeducativos estavam na condição de aluno evadido da escola regular. 
escola "DO" e "NO" sistema socioeducativo, enfatiza a necessidade de que se crie uma cultura que realmente privilegie uma política interdisciplinar de atendimento do interno, onde a escola seja parte do centro socioeducativo e não algo externo que foi instalado no centro.

Dificilmente um adolescente ou jovem irá se envolver em um processo de educação ou ressocialização caso não consiga enxergar nele um sentido real para sua vida. Então, corroboramos com Julião (2016), quando coloca que a educação da pessoa privada de liberdade deve ir além do ambiente prisional, devendo ser garantia de socialização para a vida em liberdade. Assim, muito além de discursos de educação e reinserção social, esses adolescentes e jovens precisam enxergar políticas públicas que os coloquem em contato com possibilidades e oportunidades diferentes das que tinham quando realizaram os atos infracionais que os conduziram ao cumprimento das medidas socioeducativas.

Concordamos com Costa (2006), quando afirma que tão importante quanto oferecer oportunidades é oferecer condições de realizar boas escolhas. E concordamos também com a socioeducanda que, preocupada com o futuro e cheia de desesperança, falou: "Não adianta dá o curso de alguma coisa aqui e quando chegar lá fora a gente não poder trabalhar." 20 (Socioeducanda 2, Grupo Focal do Centro CSC, grifo nosso).

Nessa fala, embasada na própria realidade, a garota denuncia que só é possível fazer boas escolhas frente às oportunidades, e é disso que eles precisam.

Compreendemos que o aluno precisa ser acolhido por um projeto ou programa que o leve a refletir sobre a própria vida e a realidade que o cerca, como propõe o "Recomece... Desenhando o futuro", mas não basta. É preciso também uma sequência didática mais rica, que integre os saberes, os horários, as atividades, os novos olhares e que possibilite ao socioeducando um melhor aprendizado e, sobretudo, condições de aplicabilidade em seu cotidiano. Embora esteja recluso em um centro socioeducativo, como disse a socioeducanda, "o pensamento está na liberdade" e é para enfrentar a própria realidade que eles querem e precisam se preparar.

Nesse sentido, finalizamos este estudo reconhecendo a grandeza da educação enquanto ferramenta de emancipação e transformação social, de modo que embasa a socioeducação e seus ideais, e a escolarização formal como fator indispensável na sociedade atual. Mas reconhecemos também o quanto essas ferramentas são impotentes quando diante da falta de políticas públicas sociais de assistência básica.

Assim, se a ideia é apontar para um programa de ressocialização do adolescente e do jovem que está no centro socioeducativo, salientamos que a educação é sim um fator indispensável, porém limitado. Então chamamos atenção do sistema para a necessidade de uma política que compreenda o jovem na sua totalidade, que comece antes da sua chegada no centro socioeducativo e não o lance à própria sorte após o cumprimento da sua medida.

\section{Referências bibliográficas}

ABRAMOVAY, Miriam et al. Violências nas escolas. Brasília: UNESCO Brasil, Rede Pitágoras, Coordenação DST/AIDS do Ministério da Saúde, Secretaria de Estado dos Direitos Humanos do Ministério da Justiça, CNPq, Instituto Ayrton Senna, UNAIDS, Banco Mundial, USAID, Fundação Ford, CONSED, UNDIME, 2002.

20 A socioeducanda se referia à dificuldade de se locomover entre os bairros com facções criminosas rivais. 
BRASIL. Lei no 8.069, de 13 de julho de 1990. Dispõe sobre o Estatuto da Criança e do Adolescente e dá outras providências. Brasília: Presidência da República.

BRASIL. Resolução CNE/CEB 3/2016. Diário Oficial da União, Brasília, 16 de maio de 2016, Seção 1, p. 6.

BRASIL. Resolução CNE/CEB 3/2016. Diário Oficial da União, Brasília, 16 de maio de 2016, Seção 1, p. 6.

BRASIL. Constituição $1988 . \quad$ Dederal, em: http://www.planalto.gov.br/ccivil_03/constituicao/constituicaocompilado.htm. Acesso em: 21 set. 2018.

BRASIL. Lei de Diretrizes e Bases da Educação Nacional. Lei número 9394, 20 de dezembro de 1996.

BUENO, J. G. S. Função social da escola e organização do trabalho pedagógico. Educar, Curitiba, n. 17, p. 101-110, 2001. Editora da UFPR. Disponível em: http://www.scielo.br/scielo.php?pid=S0104-40602001000100008\&script=sci_arttext. Acesso em: 09 de jul. 2019.

CEARÁ. Lei n.o 16.025, de 30 de maio de 2016. Dispõe sobre Plano Estadual de Educação (2016/2024). Anexo único. 34p. 2016.

CEARÁ. Secretaria do Trabalho e Desenvolvimento Social. Regimento Interno: Unidades de Medidas Socioeducativas do Estado do Ceará/Banco Interamericano de Desenvolvimento; Governo do Estado do Ceará, PROARES II. Ceará: Governo do Estado do Ceará, 2013. Disponível em: https://www.seas.ce.gov.br/wpcontent/uploads/sites/35/2018/06/regimento-interno-2015.pdf. Acesso em: 12 mar. 2019.

COSTA, Antonio Carlos Gomes da. (Coord). Parâmetros para formação do socioeducador: uma proposta inicial para reflexão e debate. Brasília: Secretaria Especial dos Direitos Humanos, 2006b.

COSTA, Antonio Carlos Gomes da. Socioeducação: Estrutura e funcionamento da comunidade educativa. Brasília: Secretaria Especial dos Direitos Humanos, 2006a. 156 p.

DAYRELL, Juarez. A Escola "Faz" As Juventudes? Reflexões em torno da socialização juvenil. Educ. Soc., Campinas, v. 28, n. 100, p. 1105-1128, out. 2007.

FRAGOSO, G. M. Biblioteca na escola. Rev. ACB: Biblioteconomia em Santa Catarina, v. 7, n. 1, 2002. Disponível em: https://revista.acbsc.org.br/racb/article/view/380/461. Acesso em: 06 jul. 2019.

FREIRE, Paulo. Pedagogia do oprimido. 17. ed. Rio de Janeiro: Paz e Terra. 1987.

FREIRE, Paulo. Pedagogia da autonomia: saberes necessários à prática educativa. São Paulo: Paz e Terra, 1997.

FREIRE, Paulo. Pedagogia da autonomia: saberes necessários à prática educativa. São Paulo: Paz e Terra, 1997.

FREIRE, Paulo. A mensagem de Paulo Freire: textos de Paulo Freire selecionados pelo INODEP. São Paulo: Nova Crítica, 1977. 
FIALHO, Lia Machado Fiuza. A experiência socioeducativa de internação na vida de jovens em conflito com a lei. 2012. Tese (doutorado) - Universidade Federal do Ceará, Faculdade de Educação, Programa de Pós-Graduação em Educação Brasileira, Fortaleza, 2012. $359 \mathrm{f}$.

GADOTTI, Moacir. Educação de Adultos como Direito Humano. São Paulo: Editora e Livraria Instituto Paulo Freire, 2009.

JULIÃO, Elionaldo Fernandes. Escola na ou da prisão? Cad. Cedes, Campinas, v. 36, n. 98, p. 25-42, jan.-abr., 2016.

MACEDO, Elizabeth. Currículo e conhecimento: aproximações entre educação e ensino. Cadernos de Pesquisa, v. 42, n.147, p. 716-737, set./dez. 2012. Disponível em: http://publicacoes.fcc.org.br/ojs/index.php/cp/article/view/4/17. Acesso em: 06 jul. 2019.

OLIVEIRA, Cynthia Bisinoto Evangelista de. Colóquio 2.7 - Direito à educação para adolescentes, jovens e adultos em situação socioeducativas e para pessoas privadas de liberdade. In: BRASIL. CONAE 2014. Coletânea de Textos. Brasília, 2014. Disponível em: http://conae2014.mec.gov.br/images/doc/Sistematizacao/Impressos/

ColetaneadeTextos.pdf. Acesso em: 01 jul. 2019.

PIAGET, Jean. Epistemologia Genética. Trad. Álvaro Cabral. 3. ed. Martins Fontes: São Paulo, 2007.

SAVIANI, Dermeval. Pedagogia: o espaço da Educação na Universidade. Cadernos de Pesquisa, v. 37, n. 130, p. 99-134, jan./abr. 2007. Disponível em: http://www.scielo.br/pdf/cp/v37n130/06.pdf. Acesso em: 02 jun. 2019.

SAVIANI, Dermeval. Pedagogia: o espaço da Educação na Universidade. Cadernos de Pesquisa, v. 37, n. 130, p. 99-134, jan./abr. 2007. Disponível em: http://www.scielo.br/pdf/cp/v37n130/06.pdf. Acesso em: 02 jun. 2019.

ZANELLA, M. N. Bases teóricas da socioeducação: análise das práticas de intervenção e metodologias de intervenção e metodologias de atendimento do adolescente em situação de conflito com a lei. 2001. Dissertação (Mestrado) - Universidade Bandeirante (UNIBAN), Programa de Mestrado Profissional Adolescente em conflito com a Lei. São Paulo, 2011. 